Original Research

\title{
Water Photo-Oxidation Reaction on Clean and Doped Two-Dimensional Graphitic $\mathbf{C}_{2} \mathbf{N}$
}

Tyler Campbell, Sergey Stolbov *

Physics Department University of Central Florida, Orlando, Florida, USA; E-Mails: campbellt@knights.ucf.edu; Sergey.Stolbov@ucf.edu

* Correspondence: Sergey Stolbov; E-Mail: Sergey.Stolbov@ucf.edu

Academic Editor: Alfonso Chinnici

Special Issue: Hydrogen Energy: Sustainable Production, Storage and Utilisation

Journal of Energy and Power Technology

2020, volume 2 , issue 2

doi:10.21926/jept.2002003
Received: February 16, 2020

Accepted: April 17, 2020

Published: April 20, 2020

\begin{abstract}
In the search for new efficient photo-catalysts for hydrogen production through water splitting, the main attention has been paid to tuning the band gap width and its position with respect to vacuum level. However, actual electro-catalytic activity for the water oxidation reaction on a catalyst surface is no less important than those quantities. In this work we evaluate from first principles the thermodynamics of the reaction on relatively new candidates for water splitting: two-dimensional $\mathrm{C}_{2} \mathrm{~N}$ and that doped with phosphorus. We find that the 4-step reaction usually expected for water splitting will not proceed on these systems, resulting in oxygen atoms left strongly adsorbed to the surface. Another option, a 3-step reaction, is also found to be unfavorable. We also test an effect of higher oxygen coverage on the reaction thermodynamics, as suggested elsewhere. We find that, indeed, the doubled O-coverage makes the 4-step reaction feasible for the doped $\mathrm{C}_{2} \mathrm{~N}$. However, an unacceptably high anode potential is required to make this reaction proceed. We thus conclude that the materials under consideration may not be efficient electro-catalysts for water splitting.
\end{abstract}

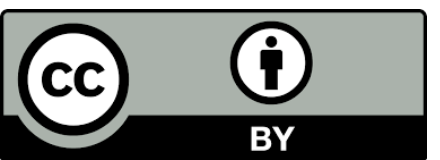

(C) 2020 by the author. This is an open access article distributed under the conditions of the Creative Commons by Attribution License, which permits unrestricted use, distribution, and reproduction in any medium or format, provided the original work is correctly cited. 


\section{Keywords}

Photo-electro-chemical water splitting; reaction thermodynamics; density functional theory; two-dimensional electro-catalysts

\section{Introduction}

Since about $85 \%$ of the United States energy supply is still provided by fossil fuels, the search for alternative clean and renewable sources of energy is of great importance. Among various alternatives, hydrogen is considered to be one of the promising solutions to this problem. However, currently, it is produced mostly through steam reforming of natural gas, which again is a non-renewable fossil fuel. Furthermore, this process generates an enormous amount of $\mathrm{CO}_{2}$. In contrast, the photocatalytic water splitting under the solar light irradiation can provide a renewable and absolutely clean energy source.

Various materials have been tested as potential photo-catalysts since Fujishima and Honda [1] first reported photo-electro-chemical water splitting. There are a number of highly active and stable photo-anodes and photo-catalysts, such as $\mathrm{TiO}_{2}$ and some other metal oxides. However, due to a wide band gap ( $\sim 3 \mathrm{eV}$ for $\mathrm{TiO}_{2}$ ), they are responsive only to the ultra-violet (UV) range of the spectrum, while the fraction of UV light in the incoming solar irradiation is only about $4 \%$. On the other hand, some semiconductors with narrower band gaps are not stable in the reaction environment. For example, $\mathrm{Cd}_{1-x} \mathrm{Zn}_{\mathrm{x}} \mathrm{S}$ suffer from photo-corrosion [2-4]. Another obstacle is that the position of the band gap with respect to the vacuum level is also critical for the process. Some progress has been achieved in search for stable photo-catalysts active under the visible-light irradiation by doping of the wide gap semiconductors such as $\mathrm{TiO}_{2}[5,6]$, or by synthesizing solid solutions, such as GaN:ZnO [7]. Photocatalytic activity in the visible light range has also been reported for other semiconductors, such as $\mathrm{ZnO}_{2}$ [8], niobate and titanate with (111) plane-type layered perovskite structure [9], nanoscale strontium titanate [10], electro-spun iron oxide fibres [11], $\mathrm{AgMO}_{3}$ (M: Ta and Nb) [12], $\mathrm{Ba}_{3} \mathrm{NiM}_{2} \mathrm{O}_{9}$ (M=Nb, Ta) [13], $\mathrm{BiVO}_{4}$ [14], $\ln _{\mathrm{x}-1} \mathrm{Ni}_{\mathrm{x}} \mathrm{TaO}_{4}$ [15], $\mathrm{Na}_{1-}$ ${ }_{x} \mathrm{La}_{x} \mathrm{Ta}_{1-x} \mathrm{Co}_{x} \mathrm{O}_{3}$ [16], as well as for $\mathrm{ZnS}-\mathrm{CulnS}_{2}-\mathrm{AgInS}{ }_{2}$ [17] solid solutions, and for the layered $\mathrm{K}_{4} \mathrm{Nb}_{6} \mathrm{O}_{17}$ structure intercalated with $\mathrm{NiO}$ [18]. However, characteristics of these materials are not optimal yet. A comprehensive description of the current status of the problem is given in a number of review articles $[19,20]$.

A relatively new direction of the search is exploring two-dimensional or quasi-two-dimensional materials. One promising system is graphitic $\mathrm{C}_{3} \mathrm{~N}_{4}\left(\mathrm{~g}-\mathrm{C}_{3} \mathrm{~N}_{4}\right)$ which has a layered structure with Van Der Waals interaction between layers [21-23]. The pristine g- $C_{3} \mathrm{~N}_{4}$ has a band gap of $2.7 \mathrm{eV}$ which is narrower than that of $\mathrm{TiO}_{2}$. Furthermore, some doping makes it even narrower. It has been reported that doping with $\mathrm{B}$ [24], P [25], Zn [26], and S [27] causes significant changes in optical properties and photocatalytic activity of $\mathrm{g}-\mathrm{C}_{3} \mathrm{~N}_{4}$.

Just recently (in 2015) a new structure, two-dimensional dicarbon nitride $\mathrm{C}_{2} \mathrm{~N}$, has been discovered [28]. More recent works [29, 30] provided more details on the properties of these materials. The band gap width of this material is found to be around $2 \mathrm{eV}$, which is very promising for photocatalytic water splitting. Other publications [31] suggest that the band gap is wider (about $2.4 \mathrm{eV}$ ). Further reports showed that some doping of $\mathrm{C}_{2} \mathrm{~N}$, such as P-doping, can make the 
band gap narrower and thus more favorable for the visible light excitation of the process in question [32, 33].

As mentioned above, the band gap width and its position with respect to vacuum level are critical characteristics of photo-anodes. In most works, authors focus on these characteristics. Selecting an appropriate cathode (a metal island on the photo-anode surface) ensures efficient charge separation setting a potential difference. Next, actual water electrolysis is supposed to happen (splitting of water, releasing protons to form $\mathrm{H}_{2}$ molecules on the cathode). In regular electrolysis, the anode catalysts facilitate the water splitting reaction, while in photo-catalysis, either photo-anode surface itself or deposited co-catalysts are used to catalyze water splitting. The best-known co-catalysts are $\mathrm{IrO}_{2}$ and $\mathrm{RuO}_{2}$ [34-36] which are usually deposited as islands on the photo-anode surface.

As mentioned above, the newly discovered two-dimensional pristine and doped $\mathrm{C}_{2} \mathrm{~N}$ can be promising photo-anodes for the visible-light excitations. However, their ability to facilitate actual water oxidation reaction has not been studied yet. Therefore, in this work we perform the first principle evaluation of thermodynamics of water oxidation on the $\mathrm{C}_{2} \mathrm{~N}$ surface and on that doped with phosphorus $\left(\mathrm{C}_{2} \mathrm{~N}-\mathrm{P}\right)$ to conclude on the efficiency of these materials for water splitting.

\section{Computational Details}

All density functional theory (DFT)-based calculations have been performed in this work using the VASP5.3 code [37] with projector augmented wave potentials [38] and with the Perdew-BurkeErnzerhof (PBE) parameterization for the exchange and correlation functional [39]. In order to maintain periodicity we use a supercell that includes a monolayer of $\mathrm{C}_{2} \mathrm{~N}$ or $\mathrm{C}_{2} \mathrm{~N}-\mathrm{P}$ with a $\sim 14 \AA$ vacuum layer. The $(4 \times 4 \times 1)$ k-point sampling in Brillouin zone used in this work provided sufficient accuracy for the characteristics obtained by integration in the reciprocal space of $\mathrm{C}_{2} \mathrm{~N}$ and $\mathrm{C}_{2} \mathrm{~N}-\mathrm{P}$. The cutoff energy of $400 \mathrm{eV}$ was used for the plane wave expansion of wave functions. To achieve structural relaxation, the atomic positions were optimized to obtain equilibrium geometric structures in which the force acting on each atom and each direction does not exceed $0.01 \mathrm{eV} / \AA$. To characterize the strength of the bonding between a reaction intermediate $X$ and the catalyst surface, we used the binding energy defined as follows:

$$
E_{B}(\mathrm{X})=E_{\text {tot }}(\text { surface })+E_{\text {tot }}(\mathrm{X})-E_{\text {tot }}(\mathrm{X} / \text { surface })
$$

where the three $E_{\text {tot }}$ terms denote the total energy per supercell calculated for the clean surface; the isolated (and neutral) intermediate $\mathrm{X}=\mathrm{O}, \mathrm{OH} \mathrm{OOH}$; and $\mathrm{X}$ adsorbed on the surface, respectively.

The Xcrysden software [40] has been used to plot geometric structures of the systems under consideration.

\section{Thermodynamics of the Water Oxidation Reaction}

The following multi-step reaction leads to splitting water molecules by releasing protons, which in further steps form hydrogen molecules. Norskov and coauthors have considered the following four-step reaction pathway [41]:

$$
\mathrm{H}_{2} \mathrm{O}+{ }^{*} \rightarrow \mathrm{HO}^{*}+\mathrm{H}^{+}+\mathrm{e}^{-}
$$




$$
\begin{aligned}
& \mathrm{HO}^{*} \rightarrow \mathrm{O}^{*}+\mathrm{H}^{+}+\mathrm{e}^{-} \\
& \mathrm{O}^{*}+\mathrm{H}_{2} \mathrm{O} \rightarrow \mathrm{HOO}^{*}+\mathrm{H}^{+}+\mathrm{e}^{-} \\
& \mathrm{HOO}^{*} \rightarrow \mathrm{O}_{2}+{ }^{*}+\mathrm{H}^{+}+\mathrm{e}^{-}
\end{aligned}
$$

where "*" denotes an adsorption site on the catalyst's surface. In fact, this is the inverse to the oxygen reduction reaction (ORR) on the $\mathrm{Pt}(111)$ surface evaluated earlier by the same group [42]. However, as shown in Ref. 41, the requirements for formation of hydroperoxyl $\mathrm{OOH}$ are different for this reaction on Pt. More specifically, a significant O-coverage of the surface is required to make the step described by Eq. 4 favorable. For oxide catalysts, the pathway may be different due to surface oxygen in the reaction [43].

In order to evaluate the reaction thermodynamics, we apply a well-developed approach [41, 42] to calculate the free energy of each reaction state, build free energy diagrams, and use the maximum energy separation between reaction steps as an estimate of the minimum potential needed to set the reaction.

Since each reaction step involves a charge transfer $\left(\mathrm{H}^{+}+\mathrm{e}^{-}\right)$an approximation is needed to describe its contribution to the free energy. We use a widely accepted approximation in which a chemical potential of $\mathrm{H}^{+}+\mathrm{e}^{-}$equals to one-half of the chemical potential of an $\mathrm{H}_{2}$ molecule [41]. We calculate the free energy of each reaction state with respect to the free energy of the initial state (clean catalyst surface plus two water molecules in gas phase). In other words, we calculate the difference $\Delta G$ between the free energy of a given state and the initial state:

$$
\Delta G=\Delta E+\triangle Z P E-T \Delta S-n e U
$$

Here $\triangle E$ is the difference in DFT total energies between a given state and the initial state, $\triangle Z P E$ is the difference in zero-point energies, $T \Delta S$ is the difference in entropic contributions and $n e U$ is the contribution to $\Delta G$ of electrostatic energy if the electrode potential $U$ is not zero: $n$ is the number the protons released while the reaction proceeds from the initial state to a given state, and $e$ is the electron charge. Considering these differences has a clear physical meaning. Furthermore, it is easy to calculate. Calculating $\Delta E$ allows us to exclude the total energies values and operate with well-defined binding energy of the reaction intermediates [44]. For example, for the states $\mathrm{O}^{*}$ and $\mathrm{OH}^{*}$, described by Eqs. 3 and 4, such energy difference can be expressed as:

$$
\begin{aligned}
& \Delta E(O)=E_{\text {tot }}\left(\mathrm{H}_{2}\right)+E_{\text {tot }}(\mathrm{O})-E_{\text {tot }}\left(\mathrm{H}_{2} \mathrm{O}\right)-E_{B}\left(\mathrm{O}^{*}\right) \\
& \Delta E(\mathrm{OH})=1 / 2 E_{\text {tot }}\left(\mathrm{H}_{2}\right)+E_{\text {tot }}(\mathrm{OH})-E_{\text {tot }}\left(\mathrm{H}_{2} \mathrm{O}\right)-E_{B}\left(O \mathrm{H}^{*}\right)
\end{aligned}
$$

The first three terms on the right side of Eqs. (7) and (8) represent the total energy of molecules in gas phase, which are constants. Therefore, in these equations, only the binding energy $E_{B}$ terms depend on the properties of the catalyst surface. The $\triangle Z P E$ and $T \triangle S$ values can be calculated in a similar way excluding contributions of the catalyst surface to these numbers.

Zero point energy of adsorbed molecules may have significant values $(0.3-0.5 \mathrm{eV})$. However, according to our previous experience, their changes from one catalyst surface to the other are negligible $[45,46]$. In this work we thus use earlier obtained numbers. The entropic contribution $T \Delta S$ is approximated by the gas-phase entropy of the reactants or intermediates, which is taken from the NIST data base [47] (for adsorbed species translational and rotational contributions are subtracted). 


\section{Results and Discussion}

Since binding energy values of the reaction intermediates are critical in determining the reaction thermodynamics, we start with calculating $E_{B}$ for $C_{2} N$ and $C_{2} N-P$. To evaluate the binding process, we follow the reaction sequence shown in Eqs. (1) - (4). In other words, since $\mathrm{OH}$ is the first species bound to the surface, we first find the favorable adsorption site for hydroxyl OH. Next, for that site we remove $\mathrm{H}$ from $\mathrm{OH}$, leaving atomic oxygen at the site and calculate its binding energy, etc. The results of the calculation of $E_{B}(\mathrm{OH})$ on non-equivalent sites are show in Table 1 and Table 2. These sites are shown in Figure 1 . As seen from the tables, for $\mathrm{C}_{2} \mathrm{~N}, \mathrm{OH}$ preferred to bind to $\mathrm{N}$, while for $\mathrm{C}_{2} \mathrm{~N}-\mathrm{P}$, the preferred site is $\mathrm{P}$. We thus use these sites for $\mathrm{O}$ adsorption for evaluating the step described in Eq.2 We find the $\mathrm{O}$ binding energy to be $3.28 \mathrm{eV}$ and $5.30 \mathrm{eV}$ for the pristine and $P$-doped $C_{2} N$, respectively.

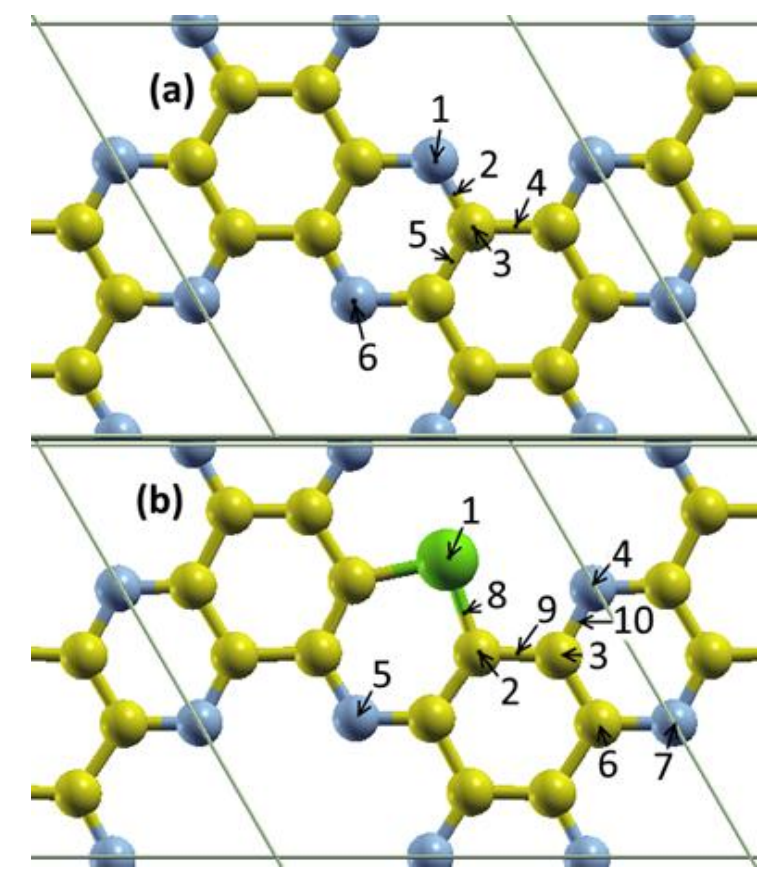

Figure 1 Inequivalent adsorption sites for which the binding energy of $\mathrm{OH}$ has been calculated on the pristine $\mathrm{C}_{2} \mathrm{~N}(\mathrm{a})$ and phosphorus-doped $\mathrm{C}_{2} \mathrm{~N}(\mathrm{~b})$.

Table $1 \mathrm{OH}$ binding energy on non-equivalent sites of $\mathrm{C}_{2} \mathrm{~N}$.

\begin{tabular}{lccccc}
\hline Binding Site & 1 & 2 & 3 & 4 & 5 \\
\hline $\begin{array}{l}\text { Binding Energy } \\
(\mathrm{eV})\end{array}$ & 1.774 & 1.190 & 1.190 & 1.051 & 0.968 \\
\hline
\end{tabular}

Table $2 \mathrm{OH}$ binding energy on non-equivalent sites of $\mathrm{C}_{2} \mathrm{~N}-\mathrm{P}$.

\begin{tabular}{lllllllllll}
\hline Binding Site & 1 & 2 & 3 & 4 & 5 & 6 & 7 & 8 & 9 & 10 \\
\hline $\begin{array}{l}\text { Binding Energy } \\
(\mathrm{eV})\end{array}$ & 3.186 & 1.419 & 1.258 & 1.382 & 0.866 & 1.279 & 2.139 & 3.051 & 1.427 & 1.331 \\
\hline
\end{tabular}


In the next step (Eq. 3), as a water molecule approaches $O$ adsorbed to the surface, it leaves a proton and the remaining $\mathrm{OH}$ is supposed to bind to $\mathrm{O}$ to form an $\mathrm{OOH}$ radical still adsorbed to the surface. To model this process we brought an $\mathrm{OH}$ molecule to the adsorbed $\mathrm{O}$ to make the $\mathrm{O}-\mathrm{O}$ distance the same as it is in free $\mathrm{OOH}$ and relaxed the system. Upon relaxation, for both $\mathrm{C}_{2} \mathrm{~N}$ and $\mathrm{C}_{2} \mathrm{~N}-\mathrm{P}, \mathrm{OOH}$ was not formed: the $\mathrm{O}-\mathrm{OH}$ bond was not made and $\mathrm{OH}$ drifted to somewhere in the vacuum region. It is worth mentioning that a similar result has been reported for this reaction on the $\mathrm{Pt}(111)$ and $\mathrm{Au}(111)$ surface [41]. We can thus conclude that the four step reaction (Eqs. 1 - 4) will not proceed for both $C_{2} N$ and $C_{2} N-P$.

In this case, an alternative resolution could be a three step reaction in which two $\mathrm{O}$ adsorbed to the surface may make an $\mathrm{O}_{2}$ molecule which then can be released. The two $\mathrm{O}$ can be adsorbed on the neighboring $\mathrm{N}$ atoms, since binding $\mathrm{O}$ to $\mathrm{N}$ is much stronger than to $\mathrm{C}$. For example, in the case of pristine $\mathrm{C}_{2} \mathrm{~N}$, one $\mathrm{O}$ atom can be adsorbed on site 1 (see Figure 1 ) and the other to the closest $\mathrm{N}$ site to the left. To make $\mathrm{O}_{2}, \mathrm{O}$ atoms must come closer to each other. That can happen due to diffusion of one of them. To diffuse, the $\mathrm{O}$ atom adsorbed on the site 1 has first to move to the $\mathrm{C}$ atom (site 4). We calculated the binding energy of $\mathrm{O}$ on that site and found it to be equal to $1.8 \mathrm{eV}$ and $4.15 \mathrm{eV}$, for $\mathrm{C}_{2} \mathrm{~N}$ and $\mathrm{C}_{2} \mathrm{~N}-\mathrm{P}$, respectively. The changes in energy upon such diffusion are +1.4 $\mathrm{eV}$ and $+1.15 \mathrm{eV}$ for $\mathrm{C}_{2} \mathrm{~N}$ and $\mathrm{C}_{2} \mathrm{~N}-\mathrm{P}$, respectively. These numbers provide the minimum possible activation energy barriers for these materials. We can thus estimate the highest diffusion rates for these energy barriers, using:

$$
R=D^{*} \exp \left(-\Delta E / k_{B} T\right)
$$

where $D$ is the pre-factor (a reasonable estimate for light atoms is $10^{13} 1 / \mathrm{s}$ ), $\Delta E$ is the barrier height, and $k_{B}$ is the Boltzmann constant. Using these numbers, we obtain $\mathrm{R}$ for room temperature to be equal $4.8 * 10^{-12} 1 / \mathrm{s}$ and $1.1 * 10^{-7} 1 / \mathrm{s}$ for $C_{2} \mathrm{~N}$ and $\mathrm{C}_{2} \mathrm{~N}-\mathrm{P}$, respectively. These are very low rates suggesting that this mechanism for both materials is not favorable. Importantly, this diffusion does not involve a charge transfer, therefore, the electrode potential will not help the diffusion to proceed anyhow.

Authors of Ref. 41 reported that according to their calculation an increase in oxygen coverage over the $\mathrm{Pt}(111)$ and $\mathrm{Au}(111)$ surfaces makes formation of $\mathrm{OOH}$ favorable, meaning that the four step reaction may proceed in this case. This is a reasonable result: adsorbed $\mathrm{O}$-atoms are negatively charged, so if the coverage is large, $\mathrm{O}-\mathrm{O}$ repulsion increases the total energy and thus decreases the $\mathrm{O}$ binding energy which may make the adsorption of $\mathrm{OH}$ on $\mathrm{O}$ favorable in order to form $\mathrm{OOH}$. Therefore, we evaluate this mechanism here. We allow another $\mathrm{O}$ atom to adsorb on sites 6 and 5 in $\mathrm{C}_{2} \mathrm{~N}$ and $\mathrm{C}_{2} \mathrm{~N}-\mathrm{P}$, respectively and evaluate the reaction thermodynamics for these cases. In other words, we calculate the binding energy and free energy for the four-step reaction intermediates. We find that even for higher $\mathrm{O}$ coverage $\mathrm{OOH}$ does not form on $\mathrm{C}_{2} \mathrm{~N}$. However, it does form on $\mathrm{P}$-sites of $\mathrm{C}_{2} \mathrm{~N}$-P. The calculation results are shown in Table 3.

Table 3 Binding energy and free energy of the four-step reaction intermediates on P-site of $\mathrm{C}_{2} \mathrm{~N}-\mathrm{P}$.

\begin{tabular}{ccc}
\hline $\mathrm{C}_{2} \mathrm{~N}-\mathrm{P}$ & $\mathrm{E}_{\mathrm{B}}, \mathrm{eV}$ & $\Delta \mathrm{G}, \mathrm{eV}$ \\
\hline $\mathbf{O H}$ & 3.36 & 0.23 \\
$\mathbf{O}$ & 4.94 & 0.92 \\
$\mathrm{OOH}$ & 1.40 & 3.53 \\
\hline
\end{tabular}




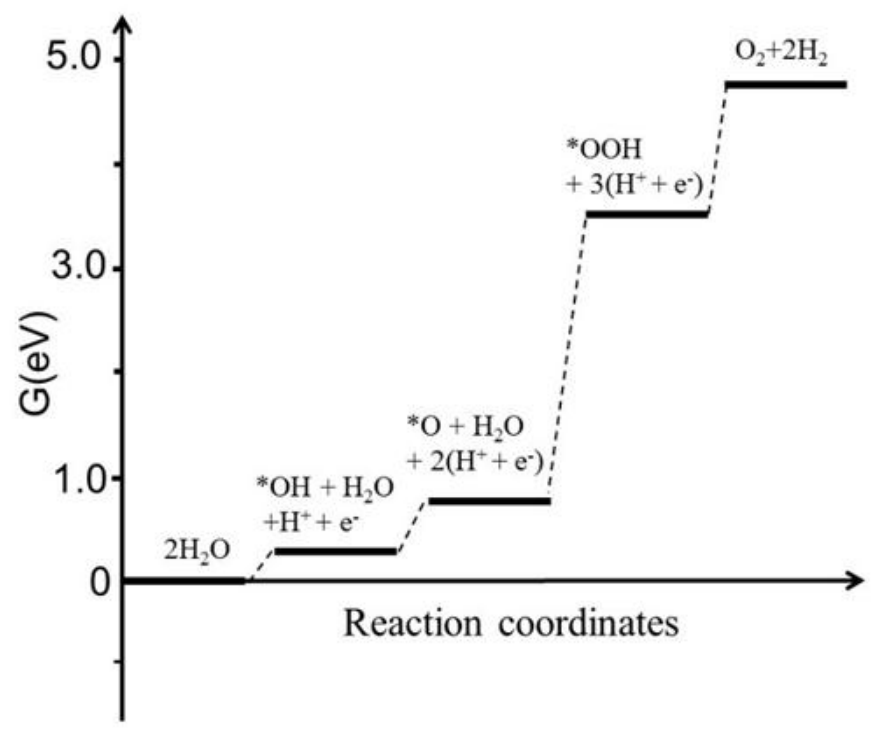

Figure 2 Free energy diagram for water splitting on $\mathrm{C}_{2} \mathrm{~N}-\mathrm{P}$.

In Figure 2, we show the free energy diagram built for this reaction at zero electrode potential. The highest energy separation between the reaction steps determines the onset potential, the potential at which the reaction will be facilitated. [41] We find it to be equal to $2.79 \mathrm{~V}$. This number appears to be too large. For Pt(111), for example, it is reported to be $1.9 \mathrm{~V}$. [41] We thus conclude that both $\mathrm{C}_{2} \mathrm{~N}$ and $\mathrm{C}_{2} \mathrm{~N}-\mathrm{P}$ surfaces are not active (not efficient) electro-catalysts for water splitting. There is another issue related to these materials when considering them as photoanodes. For photo-anodes, the band-gap width is a critical value. The materials are two dimensional with Van der Waals interaction between layers. That means that only the top layer may really provide holes to the surface. In other words, even if not a single layer is used as a photo-anode, the width of a local band gap created in the top layer is critical. As we show here, the reaction can proceed only if oxygen coverage is high. In this case, one can expect that the Oatoms bound to the surface will significantly disrupt the electronic structure and distort the gap. To study this effect we calculated the total density of electronic states (TDOS) for $\mathrm{C}_{2} \mathrm{~N}$ and $\mathrm{C}_{2} \mathrm{~N}-\mathrm{P}$ covered by oxygen as considered above. The results are shown in Figure 3.
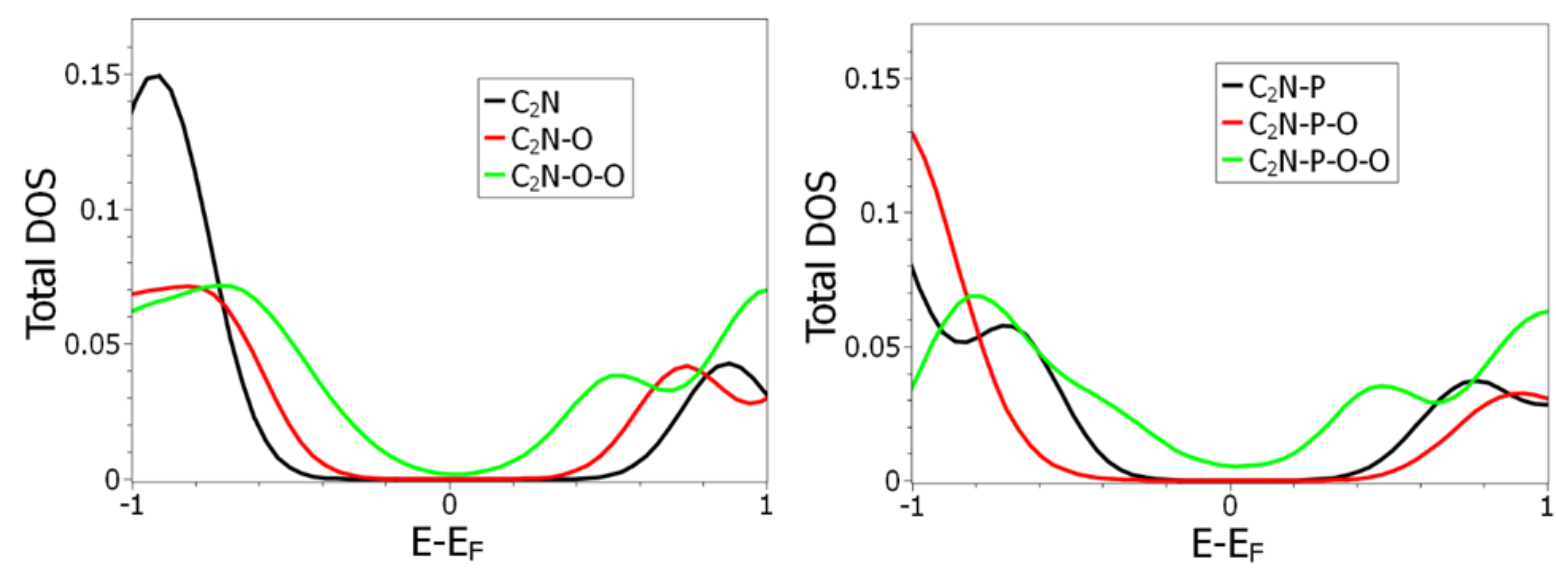

Figure 3 Change in the total densities of electronic states upon addition of $\mathrm{O}$ atoms to $\mathrm{C}_{2} \mathrm{~N}(\mathrm{a})$ and $\mathrm{C}_{2} \mathrm{~N}-\mathrm{P}(\mathrm{b})$ surfaces. 
The results show that the gap is closed upon oxygen adsorption for both materials. Of course, the calculations were performed within DFT and the gap width is underestimated. However, the obtained effect of the $\mathrm{O}$ adsorbed to the surfaces may be reasonable - the distortion of the band gap may be critical for the gap and thus the properties of the photo-anode. This is another reason why increasing oxygen coverage does not seem to make $\mathrm{C}_{2} \mathrm{~N}$ and $\mathrm{C}_{2} \mathrm{~N}-\mathrm{P}$ surfaces viable candidates for photocatalytic water splitting.

\section{Conclusions}

To estimate the activity of two-dimensional $\mathrm{C}_{2} \mathrm{~N}$ and that doped with phosphorus toward electro-catalytic water splitting, we applied a density-functional theory based computational approach to evaluate the thermodynamics of the reaction along the pathway presented in Eqs. (2 -5). To this end, we calculated the binding energy of the reaction intermediates and free energy of the reaction steps. We found that the reaction cannot proceed to the step described in Eq. (4) because the formation of $\mathrm{OOH}$ by adsorbing the $\mathrm{OH}$ radical to an adsorbed $\mathrm{O}$-atom is not energetically favorable for such high adsorption energy of the O-atom to the surface. The threestep pathway in which two O-atoms adsorbed to the surface diffuse to form $\mathrm{O}_{2}$ is found to occur at a negligible rate. We have also considered the effect of a higher $\mathrm{O}$ coverage on the reaction. We found that if an extra $\mathrm{O}$-atom is adsorbed to each unit cell, $\mathrm{OOH}$ formation is possible for $\mathrm{C}_{2} \mathrm{~N}-\mathrm{P}$. However, the calculated reaction energetics suggest that for this reaction to proceed, the necessary electrode potential is too high. Furthermore, the density of states calculations show that increasing O-atom coverage of the two-dimensional surfaces destroys the band gap. We thus conclude that the two-dimensional $\mathrm{C}_{2} \mathrm{~N}$ and $\mathrm{C}_{2} \mathrm{~N}-\mathrm{P}$ may not be efficient photo-electro catalysts for water splitting.

\section{Acknowledgments}

The authors acknowledge the University of Central Florida Advanced Research Computing Center for providing computational resources and support that have contributed to results reported herein. URL: https://arcc.ist.ucf.edu.

\section{Author Contributions}

Tyler Campbell: performed all calculations and preprocessing work and participated in interpretation of the results. Sergey Stolbov: Planned the research, participated in interpretation of the results, drafted and revised the manuscript.

\section{Competing Interests}

The authors have declared that no competing interests exist.

\section{References}

1. Fujishima A, Honda K. Electrochemical of water at a semiconductor electrode. Nature. 1972; 238: 37-38. 
2. Kudo A, Miseki Y. Heterogeneous photocatalyst materials for water splitting. Chem Soc Rev. 2009; 38: 253-278.

3. del Valle F, Ishikawa A, Domen K, Villoria de la Mano JA, Sánchez-Sánchez MC, González ID, et al. Influence of $\mathrm{Zn}$ concentration in the activity of $\mathrm{Cd}_{1-\mathrm{x}} \mathrm{Zn}_{\mathrm{x}} \mathrm{S}$ solid solutions for water splitting under visible light. Catal Today. 2009; 143: 51-56.

4. Wang X, Liu G, Chen ZG, Li F, Lu GQ, Cheng HM. Efficient and stable photocatalytic $\mathrm{H}_{2}$ evolution from water splitting by $\left(\mathrm{Cd}_{0.8} \mathrm{Zn}_{0.2}\right) \mathrm{S}$ nanorods. Electrochem Commun. 2009; 11: 1174.

5. Asahi R, Morikawa T, Ohwaki T, Aoki K, Taga Y. Visible-light photocatalysis in nitrogen-doped titanium oxides. Science. 2001; 293: 269-271.

6. Ni M, Leung MKH, Leung DYC, Sumathy K. A review and recent developments in photocatalytic water-splitting using $\mathrm{TiO}_{2}$ for hydrogen production. Renew Sust Energ Rev. 2007; 11: 401-425.

7. Maeda K, Teramura K, Lu D, Takata T, Saito N, Inoue Y, et al. Photocatalyst releasing hydrogen from water. Nature. 2006; 440: 295.

8. Reddy VR, Hwang DW, Lee JS. Photocatalytic water splitting over $\mathrm{ZrO}_{2}$ prepared by precipitation method. Korean J Chem Eng. 2003; 20:1026-1029.

9. Miseki $Y$, Kato $H$, Kudo A. Water splitting into $\mathrm{H} 2$ and $\mathrm{O} 2$ over niobate and titanate photocatalysts with (111) plane-type layered perovskite structure. Energ Environmen Sci. 2009; 2: 306-314.

10. Townsend TK, Browning ND, Osterloh FE. Nanoscale strontium titanate photocatalysts for overall water splitting. ACS Nano. 2012; 6: 7420-7426.

11. Santangelo S, Frontera P, Pantò F, Stelitano S, Marelli M, Patanè S, et al. Effect of Ti-or Sidoping on nanostructure and photo-electro-chemical activity of electro-spun iron oxide fibres. Int J Hydrogen Energ. 2017; 42: 28070-28081.

12. Kato $\mathrm{H}$, Kobayashi $\mathrm{H}$, Kudo $\mathrm{A}$. Role of $\mathrm{Ag}^{+}$in the band structures and photocatalytic properties of $\mathrm{AgMO}_{3}$ (M: Ta and $\mathrm{Nb}$ ) with the perovskite structure. J Phys Chem B. 2002; 106: 1244112447.

13. Xu B, Zhang WF, Liu XY, Ye JH, Zhang WH, Shi L, et al. Photophysical properties and electronic structure of the perovskite photocatalysts $\mathrm{Ba}_{3} \mathrm{NiM}_{2} \mathrm{O}_{9}(\mathrm{M}=\mathrm{Nb}, \mathrm{Ta})$. Phys Rev B. 2007; 76: 125109-1-6.

14. Kudo A. Recent progress in the development of visible light-driven powdered photocatalysts for water splitting. Int J Hydrogen Energ. 2007; 32: 2673-2678.

15. Zou Z, Ye J, Sayama K, Arakawa H. Direct splitting of water under visible light irradiation with an oxide semiconductor photocatalyst. Nature. 2001; 414: 625-627.

16. Yi ZG, Ye JH. Band gap tuning of $\mathrm{Na}_{1-x} \mathrm{La}_{x} \mathrm{Ta}_{1-\mathrm{x}} \mathrm{CO}_{\mathrm{x}} \mathrm{O}_{3}$ solid solutions for visible light photocatalysis. Appl Phys Lett. 2007; 91: 254108-1-3.

17. Tsuji I, Kato $\mathrm{H}$, Kudo A. Visible-light-induced $\mathrm{H}_{2}$ evolution from an aqueous solution containing sulfide and sulfite over a $\mathrm{ZnS}^{-C_{1}} \mathrm{InS}_{2}$-AgInS $\mathrm{S}_{2}$ solid-solution photocatalyst. Angew Chem Int Ed Engl. 2005; 44: 3565-3568.

18. Lin $\mathrm{HY}$, Lee $\mathrm{TH}$, Sie $\mathrm{CY}$. Photocatalytic hydrogen production with nickel oxide intercalated $\mathrm{K}_{4} \mathrm{Nb}_{6} \mathrm{O}_{17}$ under visible light irradiation. Inter J Hydrogen Energ. 2008; 33: 4055-4063.

19. Maeda K, Domen K. Photocatalytic water splitting: Recent progress and future challenges. J Phys Chem Lett. 2010; 1: 2655. 
20. Navarro RM, Alvarez-Galván MC, Villoria de la Mano JA, Al-Zahrani SM, Fierro JLG. A framework for visible-light water splitting. Energy Environ Sci. 2010; 3: 1865.

21. Wang X, Maeda K, Thomas A, Takanabe K, Xin G, Carlsson JM, et al. A metal-free polymeric photocatalyst for hydrogen production from water under visible light. Nature Mat. 2009; 8: 76-80.

22. Zheng Y, Liu J, Liang J, Jaroniec M, Qiao SZ. Graphitic carbon nitride materials: controllable synthesis and applications in fuel cells and photocatalysis. Energy Environ Sci. 2012; 5: 67176731.

23. Stolbov S, Zuluaga S. Sulfur doping effects on the electronic and geometric structures of graphitic carbon nitride photocatalyst: insights from first principles. J Phys Condensed Matter. 2013; 25: 085507.

24. Yan SC, Li ZS, Zou ZG. Photodegradation of rhodamine B and methyl orange over borondoped g-C3N4 under visible light irradiation. Langmuir. 2010; 26: 3894.

25. Zhang Y, Mori T, Ye J, Antonietti M. Phosphorus-doped carbon nitride solid: Enhanced electrical conductivity and photocurrent generation. J Am Chem Soc. 2010; 132: 6294.

26. Yue B, Li Q, Iwai H, Kako T, Ye J. Hydrogen production using zinc-doped carbon nitride catalyst irradiated with visible light. Sci Technol Adv Mater. 2011; 12: 034401.

27. Liu G, Niu P, Sun C, Smith SC, Chen Z, Qing G, et al. Unique electronic structure induced high photoreactivity of sulfur-doped graphitic $\mathrm{C}_{3} \mathrm{~N}_{4}$. J Am Chem Soc. 2010; 132: 11642-11648.

28. Zhang J, Sun J, Maeda K, Domen K, Antonietti M, Fu X. Sulfur-mediated synthesis of carbon nitride: Band-gap engineering and improved functions for photocatalysis. Energy Environ Sci. 2011; 4: 675.

29. Mahmood J, Lee EK, Jung M, Shin D, Jeon IY, Jung SM, et al. Nitrogenated holey twodimensional structures. Nature Commun. 2015; 6: 6486.

30. Yu S, Rao YC, Duan XM. Modulating the properties of monolayer $\mathrm{C}_{2} \mathrm{~N}$ : A promising metal-free photocatalyst for water splitting. Chinese Physics B. 2017; 26: 087301.

31. Kishore MRA, Sjåstad AO, Ravindran P. Influence of hydrogen and halogen adsorption on the photocatalytic water splitting activity of $\mathrm{C}_{2} \mathrm{~N}$ monolayer: A first-principles study. Carbon. 2019; 141: 50-58.

32. Makaremi M, Grixti S, Butler KT, Ozin GA, Singh CV. Band engineering of carbon nitride monolayers by N-type, P-type, and isoelectronic doping for photocatalytic applications. ACS Appl Mater Interfaces. 2018; 10: 11143-11151.

33. Zhang $H$, Zhang $X$, Yang G, Zhou X. Point defect effects on photoelectronic properties of the potential metal-free $\mathrm{C}_{2} \mathrm{~N}$ photocatalysts: Insight from first-principles computations. J Phys Chem C. 2018; 122; 5291-5302.

34. Ma DW, Wang $Q$, Yan $X$, Zhang $X$, He C, Zhou D, et al. 3d transition metal embedded $C_{2} N$ monolayers as promising single-atom catalysts: A first-principles study. Carbon. 2016; 105: 463-473.

35. Ashwin Kishore MR, Ravindran P. Tailoring the electronic band gap and band edge positions in the $\mathrm{C}_{2} \mathrm{~N}$ monolayer by $\mathrm{P}$ and as substitution for photocatalytic water splitting. J Phys Chem C. 2017; 121: 22216-22224.

36. Ma $B$, Wen $F$, Jiang $H$, Yang J, Ying $P$, Li C. The synergistic effects of two co-catalysts on $\mathrm{Zn}_{2} \mathrm{GeO}_{4}$ on photocatalytic water splitting. Catal Letts. 2010; $134: 78-86$ 
37. Hara M, Waraksa CC, Lean JT, Lewis BA, Mallouk TE. Photocatalytic water oxidation in a buffered Tris(2,2'-bipyridyl)ruthenium complex-colloidal IrO2 system. J Phys Chem A. 2000; 104: 5275-5280.

38. Kresse G, Furthmüller J. Efficiency of ab-initio total energy calculations for metals and semiconductors using a plane-wave basis set. J Com put Mat Sci. 1996; 6: 15-50.

39. Kresse G, Joubert J. From ultrasoft pseudopotentials to the projector augmented-wave method. Phys Rev B. 1999; 59: 1758.

40. Perdew JP, Burke S, Ernzerhof M. Generalized gradient approximation made simple. Phys Rev Lett. 1996; 77: 3865.

41. Kokalj A. Computer graphics and graphical user interfaces as tools in simulations of matter at the atomic scale. Comp Mater Sci. 2003; 28: 155.

42. Rossmeisl J, Logadottir A, Nørskov JK. Electrolysis of water on (oxidized) metal surfaces. Chem Phys. 2005; 319: 178-184.

43. Nørskov JK, Rossmeisl J, Logadottir A, Lindqvist L, Kitchin JR, Bligaard T, et al. Origin of the overpotential for oxygen reduction at a fuel-cell cathode. J Phys Chem B. 2004; 108: 17886.

44. Ping Y, Nielsen RJ, Goddard WA. The reaction mechanism with free energy barriers at constant potentials for the oxygen evolution reaction at the $\mathrm{IrO}_{2}$ (110) surface. J Am Chem Soc. 2017; 139: 149-155.

45. Stolbov S, Alcantara Ortigoza M. Gold-doped graphene: A highly stable and active electrocatalysts for the oxygen reduction reaction. J Chem Phys. 2015; 142: 154703.

46. Zuluaga $S$, Stolbov S. Factors controlling the energetics of the oxygen reduction reaction on the Pd-Co electro-catalysts: Insight from first principles. J Chem Phys. 2011; 135: 134702.

47. Computational Chemistry Comparison and Benchmark Data Base, National Institute of Standards and Technology web site: http://www.cccbdb.nist.gov.

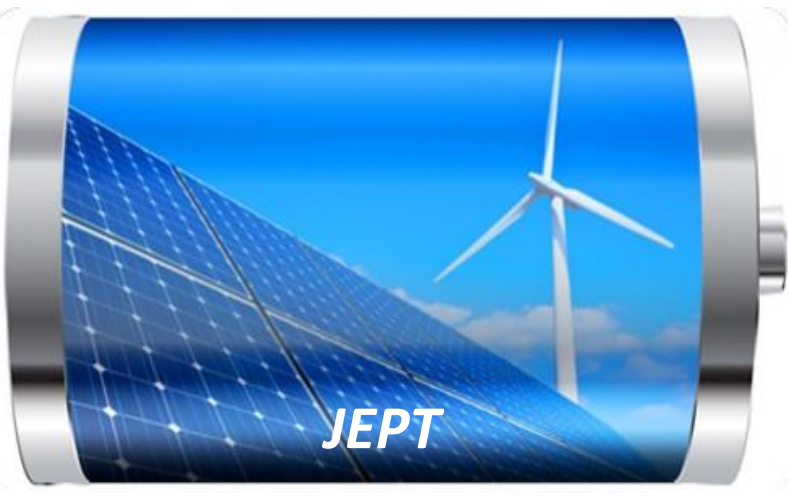

Enjoy JEPT by:

1. Submitting a manuscript

2. Joining in volunteer reviewer bank

3. Joining Editorial Board

4. Guest editing a special issue

For more details, please visit: http://www.lidsen.com/journal/jept 